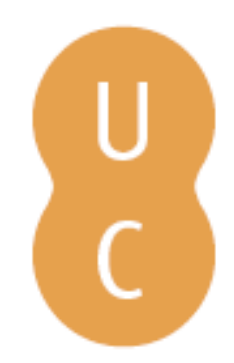

\title{
Rompalina
}

\section{Strategies for developing batteries for electric vehicles: a real options model}

Autor(es): $\quad$ Fialho, Joana; Godinho, Pedro; Costa, João Paulo

Publicado por: Imprensa da Universidade de Coimbra

URL

persistente:

URI:http://hdl.handle.net/10316.2/38151

DOI:

DOI:http://dx.doi.org/10.14195/978-989-26-1039-9_5

Accessed : $\quad$ 26-Apr-2023 14:45:01

A navegação consulta e descarregamento dos títulos inseridos nas Bibliotecas Digitais UC Digitalis, UC Pombalina e UC Impactum, pressupõem a aceitação plena e sem reservas dos Termos e Condições de Uso destas Bibliotecas Digitais, disponíveis em https://digitalis.uc.pt/pt-pt/termos.

Conforme exposto nos referidos Termos e Condições de Uso, o descarregamento de títulos de acesso restrito requer uma licença válida de autorização devendo o utilizador aceder ao(s) documento(s) a partir de um endereço de IP da instituição detentora da supramencionada licença.

Ao utilizador é apenas permitido o descarregamento para uso pessoal, pelo que o emprego do(s) título(s) descarregado(s) para outro fim, designadamente comercial, carece de autorização do respetivo autor ou editor da obra.

Na medida em que todas as obras da UC Digitalis se encontram protegidas pelo Código do Direito de Autor e Direitos Conexos e demais legislação aplicável, toda a cópia, parcial ou total, deste documento, nos casos em que é legalmente admitida, deverá conter ou fazer-se acompanhar por este aviso. 
IMPRENSA DA UNIVERSIDADE DE COIMBRA

COIMBRA UNIVERSITY PRESS

\section{ASSESSMENT \\ METHODOLOGIES}

ENERGY, MOBILITY AND OTHER

REAL WORLD APPLICATION

\section{PEDRO GODINHO \\ JOANA DIAS}

EDITORS

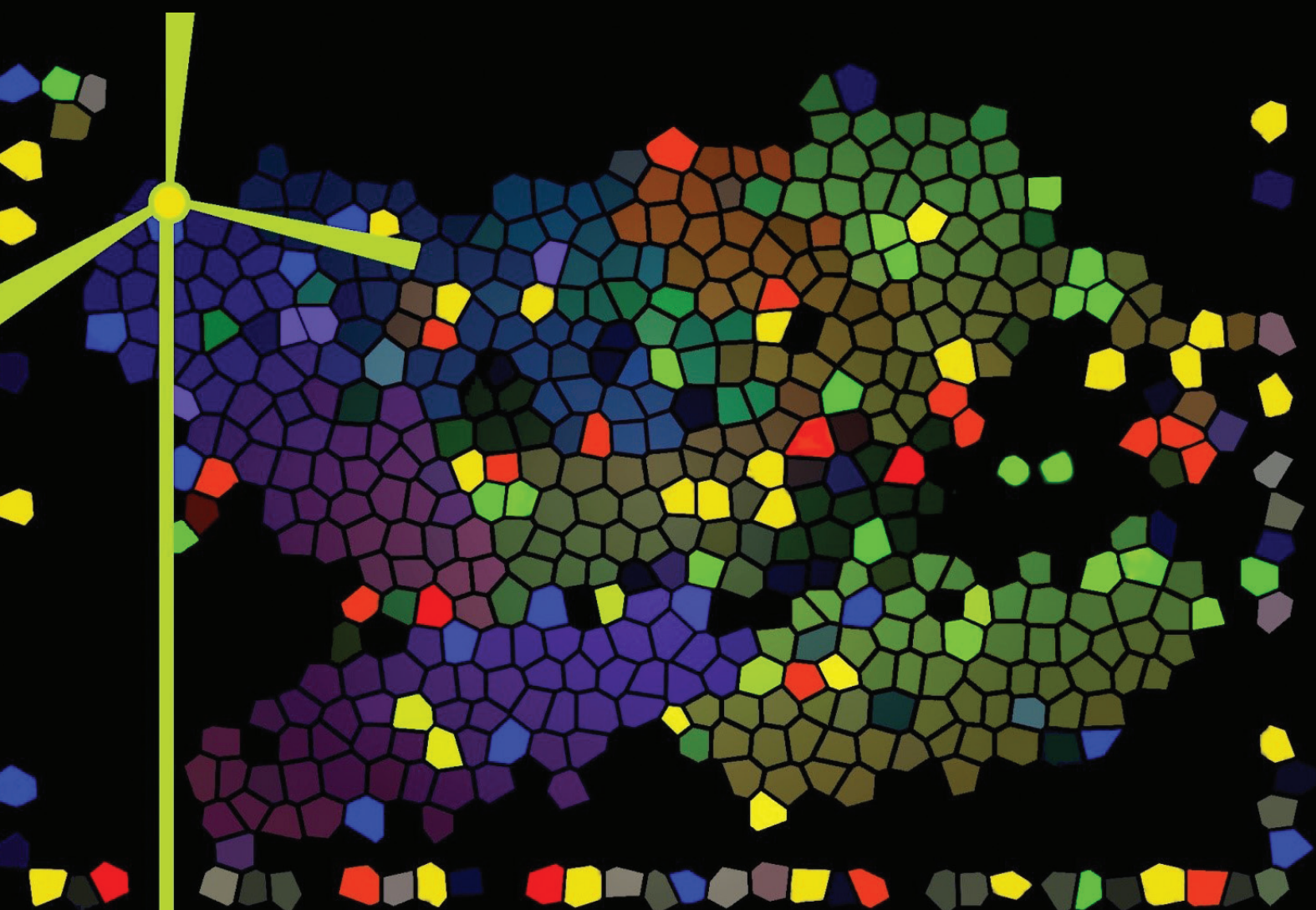




\title{
STRATEGIES FOR DEVELOPING BATTERIES \\ FOR ELECTRIC VEHICLES:A REAL OPTIONS MODEL
}

\author{
Joana Fialho ${ }^{1}$, Pedro Godinho ${ }^{2}$ and João Paulo Costa ${ }^{3}$
}

\begin{abstract}
In this article we consider the task of developing batteries for electric vehicles, and we use a tool that incorporates a real option model and Monte Carlo simulation in order to define the best strategy for managing it. We assume that different levels of resources can be used to undertake the task, leading to different average advancement speeds and different costs, and that the level of resources being used may be changed according to the way the task is developing. We present a procedure that aims at identifying the strategies that maximize the net present value of the task. The approach is used in several different scenarios, in order to define some general rules that can help managers have an idea of the resources that may be available in the future, without endangering the maximization of the net present value of the crucial tasks.
\end{abstract}

Keywords: Real options, battery development, electric vehicles, Monte Carlo simulation

\footnotetext{
${ }^{1}$ CI\&DETS - Instituto Politécnico de Viseu, Escola Superior de Tecnologia de Viseu and INESC-Coimbra (e-mail: jfialho@estv.ipv.pt)

${ }^{2}$ University of Coimbra, Faculty of Economics (e-mail: pgodinho@fe.uc.pt)

3 University of Coimbra, Faculty of Economics and INESC-Coimbra (e-mail: jpaulo@fe.uc.pt)
} 


\section{Introduction}

Public opinion has been increasingly concerned with the harmful effects of carbon dioxide gas on the environment. Such concerns extend to several different industries and technologies that resort to fossil fuels, like the automotive industry. So, automobile manufacturers have been trying to develop vehicles based on cleaner energies, which have a lesser impact on the environment. Electric Vehicles (EVs) are such an alternative to fossil fuel powered cars.

To improve the autonomy of EVs and increase the demand for such vehicles, the development of efficient batteries is crucial. The batteries are so important to the EVs that the evolution of these vehicles seems to have been driven by the developments achieved in the batteries (Magalhães, 2013).

In this work, we propose to use EV battery development as an application case for a financial valuation tool based on real options. We assume that the development of batteries is a uniform task, in the sense that it can be split into portions with identical characteristics, and that it is integrated into a major project consisting of developing a new EV. Such a task is subject to uncertainty, due to technical difficulties, market uncertainty and competitor actions, among others. Additionally, it is important to adapt the plan of action whenever unexpected events occur.

We assume that several different modes may be used to undertake this task, corresponding to the usage of different resources (e.g., different development teams), and leading to different costs and execution speeds. Managers have to decide which resources should be used to start the battery development, and in which circumstances it would be better to change the allocated resources. Each different combination of resources that can be used in the development process will be hereafter referred to as a "level of resources", and it is characterized by a cost per unit of time and a stochastic speed of task advancement.

The tool we use in this article is based on real options theory and allows the definition of a resource allocation strategy. We define a strategy as a set of rules that determine which level of resources shall be chosen, at 
each moment, and we aim to find the strategy that maximizes the value of the task of battery development. We assume that the advancement of the task is stochastic and that the project manager may change the level of resources allocated to the task while it is in progress. In order to identify the best strategy, the tool uses a method that allows the incorporation of operational flexibility and uncertainty in simulation-based valuation of projects or tasks: Least Squares Monte Carlo (originally proposed by Longstaff and Schwartz, 2001).

We present an evaluation exercise applied to a battery development task. We define several different scenarios, and extract some general conclusions by comparing the results achieved in these scenarios. We assume that a firm can either allocate a base team (Level 1) to this task or an enlarged team (Level 2) to undertake the task. These two alternatives lead to different costs and different development speeds. We build alternative scenarios to illustrate the type of results that can be obtained, and the circumstances in which each level of resources will be used. In particular, we are able to identify several cases in which it seems to be optimal to keep using the same level of resources until the end of the task, and others in which it seems best to adapt the level of resources to the way the task is developing. These rules may help managers forecasting the resources they will need in the future.

This paper is structured as follows: section 2 reviews some literature about evaluating and managing projects in the presence of uncertainty. Section 3 presents a brief review of the characteristics of batteries used in EVs. Section 4 presents a summary of the model and the evaluation procedure underlying the evaluation tool. Section 5 shows an application of the evaluation tool and presents some results. Section 6 concludes.

\section{Evaluating projects in the presence of uncertainty}

Most projects are characterized by the possibility of adapting the plan of action, according to the way the project is developing or to the arrival of new information, that is, they are characterized by operational 
flexibility. Adapting the actions in response to altered future conditions expands an investiment opportunity's value, improving the upside potential of the project and at the same time limiting the downside losses (Trigeorgis, 1993).

Traditional evaluation methods, such as the ones based on discounted cash flows, are not adequate to evaluate projects that have operational flexibility, because they assume a pre-determined and fixed plan (Yeo and Qiu, 2003). Furthermore, the realized cash flows will probably be different from what was expected, due to the uncertainty, the competitive interactions and the change that characterizes the actual marketplace (Trigeorgis, 1993). Real options methods take into account both operational flexibility and uncertainty, aiding the identification of the best decisions. A nice introduction to real options theory can be found in Dixit and Pindyck (1993).

Real options theory allows us to determine the best sequence of decisions to make in an uncertain environment, and provides the proper way to evaluate a project when such flexibility is present. The decisions are made according to the opportunities that appear along the project lifetime, which means that the optimal decision-path is chosen step by step, switching paths as events take place and opportunities appear (Cortazar et al., 2008).

The models to evaluate real options can present some difficulties, like determining the model inputs, defining relations among the input parameters or being able to solve the option pricing algorithm (Santiago and Bifano, 2005). In spite of these difficulties, following a real options perspective may have a significantly positive impact in the financial performance of a firm.

Determining real option value depends on the type of option and on the type model that is considered but, in general, determining its exact value is a complex process. Often, numerical techniques, analytical approximations or simulation are used to make the valuation process tractable. Simulation is an attractive tool to evaluate real options, because it allows us to consider the state variables as stochastic processes and, nowadays, the simulation techniques are simple, transparent and flexible (Longstaff and Schwartz, 2001). 


\section{Characteristics of batteries for electric vehicles}

The development of batteries has been slower than other areas of electronics (Zeng et al., 2014). To increase the efficiency of an EV, it is necessary to increase the number of batteries and, consequently, to increase its weight and required power.

There are many kinds of batteries, like lead-acid, nickel-cadmium (NiCd), nickel-metal hydride (NiMH) and lithium-ion batteries (LIBs) (Zeng et al., 2014). The last ones, LIBs, have presented some advantages, like higher energy density, higher cell voltage, less memory effect, low self-discharge, and very good life cycle, and are environmentally sound as well as simple to charge and maintain. Thus, these batteries are widely used in laptops, smartphones and other types of electronic devices. However, the usage of these kinds of batteries in electric vehicles still presents some difficulties, such as the need to increase their energy and power densities, improve their safety, and lower the cost (Su et al., 2014). Moreover, if there is no proper disposal for spent LIBs, the human health and environment can be endangered (Zeng et al., 2014). Several different recycling technologies have been developed for spent LIBs, but most of them are still in pilot state.

Battery development tasks are therefore crucial processes for the makers of electric vehicles. In this paper, we consider a big industrial company striving to develop a new battery, but also having other tasks to which its Research and Development (R\&D) staff may be allocated. The analysis of the better battery development strategies will result into a set of rules that may provide some general guidelines for the resource allocation policies of the company.

\section{A model and an evaluation procedure for battery development}

We assume that the development of the batteries is a homogeneous task that can be divided into several portions, termed "work units", with identical characteristics, which must be undertaken sequentially. We as- 
sume that the firm can allocate different levels of resources to the task. Different levels of resources may be related, for example, to different sizes of the team undertaking the task. Different levels of resources will lead to different costs and different development speeds. The benefits and costs resulting from completing the task will be related to the time it takes to undertake it.

We will now introduce the broad lines of the model. The detailed model can be found in Fialho (2013).

\subsection{Time to complete one work unit}

Randomness is introduced in the task advancement process by assuming that the time it takes to complete each work unit follows an exponential distribution (other authors, like Folta and Miller, 2002, use similar assumptions). Thus, the time to complete one work unit using a given level of resources, $k$, is a random variable following exponential distribution, $t^{(k)}$. The average of this random variable is defined as the reciprocal of the average number of units completed in a unit of time, when using the level of resources $k$.

\subsection{Cost of using a level of resources}

Costs are related to the usage of different levels of resources. The costs per unit of time are deterministic, and assumed to grow at a constant rate $\rho$. Considering a specific level of resources $k$, and defining $C_{x}^{(k)}$ as the instantaneous cost at time $x$, we have $d C_{x}^{(k)}=\rho C_{x}^{(k)} d x$. If level $k$ is used at time $x$, we can say that the cost of using it in the next instant $d x$ is $C_{x}^{(k)} d x$. Each time the level of resources changes, we assume that there is a "setup cost" incurred by the company. 


\subsection{Task worth}

The concepts of task worth and instantaneous task worth are used to summarize the financial impacts derived from concluding the task. The task worth is the present value of the cash flows resulting from the task, at the moment of its completion, and the instantaneous task worth is the potential value of the task worth, if it were completed at a given moment. We model the evolution of the instantaneous task worth and, when the task is concluded, we have the effective task worth. Instantaneous task worth grows at a fixed rate, and it can have stochastic jumps due to "shocks" in the value of potential cash flows.

The instantaneous change in instantaneous task worth $(R)$, in an instant of length $d x$ is denoted as $d R$, and it can be modelled as:

$$
d R=\alpha R d x+R d q
$$

Parameter $\alpha$ represents the growth rate of the instantaneous worth and $d q$ represents a jump process. The occurrence of these jumps in instantaneous task worth is assumed to follow a Poisson process with parameter $p$. So, the value of $d q$ can be defined as:

$$
d q=\left\{\begin{array}{c}
0, \text { with probability } 1-p \cdot d x \\
u, \text { with probability } p \cdot d x
\end{array}\right.
$$

Any probability distribution can be defined for $u$ and, in fact, other models for the task worth could also be used since the evaluation procedure is based on simulation. For example, a stochastic term based on a Brownian motion could easily be included, as is common in many real options models. However, in this kind of projects, expectations about future revenues and costs do not usually change in a continuous fashion, since we are not dealing with goods traded in markets in which prices change continuously (like capital markets or commodity markets). Instead, stochastic changes will usually be due to discrete events, like the entry of a competitor, shifts in the expected demand or technological changes, which may cause a significant instantaneous change in the expected cash flows.

If task completion takes longer, other risks and negative effects may affect the cash flows obtained by the company. For example, if a competitor is able to introduce, earlier, a similar product in the market, like 
new batteries, or even new electric cars, there may be a significant negative impact in the company cash flows. These effects are incorporated in the model through a penalty. This penalty is expressed by a function $g(x)$, where $x$ denotes the time. This function is positive, decreasing, and it takes values from the interval $[0,1]$. If the task finishes at time $x$, the value of the instantaneous task worth, as defined before, is multiplied by $g(x)$, in order to get the task worth. Notice that the absence of such penalty can be taken into account by defining $g(x)=1$, for all $x$.

\subsection{Net present value}

The net present value of the task is calculated by discounting all the costs regarding the use of the resource levels, as well as the final task worth, to the moment the task starts, using an appropriate discount rate. Given the stochastic nature of the model, we have to use the expected value for the net present value. Concretely, and since we use simulation, a set of paths is simulated, the best strategy and the corresponding net present value are determined for each one, and finally and average of these net present values is calculated.

\subsection{Procedure for determining the best strategy}

The procedure we use aims to define the optimal strategy to execute a task, in particular the development of batteries for an electric car. The objective of the procedure is to choose which level of resources should be used at each moment, taking into account the way the task is developing, in order to maximize the task value. In order to find the best levels of resources, we use a method similar to the Least Squares Monte Carlo (LSMC, Longstaff and Schwartz, 2001).

LSMC can be applied to estimate the value of real options. It constructs regression functions to explain the payoffs for the continuation of an option through the values of the state variables. A set of simulated 
paths of the state variables is generated. With the simulated paths, the optimal decisions are defined for the last period. From these decisions, a conditional function is built, for the penultimate period, which defines the expected value taking into account the optimal decisions of the last period and the values of the state variables. With this function, optimal decisions are defined for the penultimate period. The process continues by backward induction until the first period is reached. The use of simulation allows integrating different state variables in an easy way.

The procedure we follow is based on LSMC, but some adaptations were necessary. We start by building many paths, with different strategies. The strategies used to build the paths include executing all work units with the same level of resources or using different levels of resources to finish the task. For each strategy, and for each path, we simulate the values of the time to execute the task, using the model presented in the previous section. With the time elapsed and the levels of resources utilized, we can determine the costs, and through the model for the instantaneous task worth, we also simulate the values for the task worth. Finally, we determine the net present value of the task, for each path and for each work unit.

In this procedure, we build, by backward induction and for all work units, regression functions for the values previously calculated for the paths. These functions explain the net present value of the task as a function of different state variables: the elapsed time, the instantaneous task worth, the number of work units already finished and the level of resources being used. For the first work unit, by definition, there is no path-dependent conditional information. In order to determine the best resource level to use in the first work unit, a specific level of resources (any level) is initially assumed. With the regression functions estimated for the following work units, the best strategy and the corresponding net present value at the beginning of the task are defined for all paths, and the average net present value obtained by starting to use that resource level is calculated. The process is repeated, assuming the task starts with each possible resource level, and the level leading to the largest net present value is selected as the best one. After this procedure, the regression 
functions allow defining rules which can guide management in deciding which strategy to use at each moment, under each set of conditions (as defined by the state variables). More details about this procedure can be found in Fialho (2013).

\section{Application of the model to battery development}

This evaluation exercise intends to illustrate the type of results that a real options model, based on Monte Carlo simulation, can provide when it is applied to a battery development task. Using the previously outlined model and procedure, we will analyse the patterns that can be found in the selection of the best levels of resources to use at each moment, considering the objective of maximizing the net present value of the benefits and costs related to the task. In the simulations, we consider that the task is divided into 20 work units, and we use 2100 paths. We also assume that the firm can either allocate a base team to this task (we denote this possibility as level 1 of resource usage) or an enlarged team (we denote this possibility as level 2 of resource usage). These two alternatives lead to different costs and different development speeds.

We define several different scenarios, and extract some general conclusions by comparing the results achieved in these scenarios. The different scenarios are built around a base case (or base scenario), which we will now describe. We consider a time unit of one fortnight (two weeks) and assume that, for each level of resources, the costs per unit of time are deterministic. In order to simplify the presentation of results, we consider a monetary unit (m.u.) of $\$ 5000$.

Level 1 of resource usage is assumed to have a cost that initially amounts to $10 \mathrm{~m} . \mathrm{u}$. per unit of time, and to allow the conclusion of an average of 1.5 work units per unit of time. Level 2 allows faster, but more expensive, development of the batteries: its cost initially amounts to 25 m.u. per unit of time, and it allows the conclusion of an average of 2.5 work units per unit of time. The setup cost is equal to the cost of using the new level of resources for one unit of time. 
Costs are assumed to grow at a rate of $0.06 \%$ per fortnight (approximately the United States inflation rate in 2013). The discount rate, $r$, is assumed to be $8 \%$ per year (approximately the weighted average cost of capital of the auto \& truck industry in the United States in the beginning of 2014, according to Damodaran, 2015). This leads to a discount rate of about $0.31 \%$ per fortnight.

We assume the instantaneous task worth to be $2000 \mathrm{~m} . \mathrm{u}$. at the beginning of the task (that is, $\$ 10000000$ ). The occurrence of stochastic jumps is modelled according to a Poisson process with a rate of 0.4 , and each jump changes the instantaneous task work by a percentage given by a uniform distribution, with a minimum of $20 \%$ and a maximum of $+20 \%$. The task worth penalty (function $g(x)$, which penalizes the task worth as a function of the conclusion time) is defined in the following way: in the initial 8 units of time (16 weeks), the penalty is $0.625 \%$ per unit of time; for the subsequent 7 units of time (14 weeks), there is a penalty of $0.714 \%$ per unit of time; if the task takes more than 15 units of time ( 30 weeks) to be completed, we assume a fixed penalty of $10 \%$.

We have chosen to build alternative scenarios to understand the type of results that will be obtained, and the circumstances in which each level of resources will be used. Scenarios were built by considering two alternative levels (beyond the base case value) for each of four parameters. These parameters are the costs of resource level 2 per unit of time (C2), the task advancement per time unit in level 2 (A2), the instantaneous task worth at the beginning of the task (R0) and the task worth penalty (Pen). For each of these parameters, three levels were considered: a "high level" (H), a "medium level" (M), which is the parameter value in the base scenario, and a "low level" (L). This led to a total of 81 scenarios.

For the low level (L) of these parameters, we use the following values: for a low C2, we use costs of 15 u.m. per unit of time; for a low A2, we use an average advancement rate of 1.8 work units per unit of time; for a low R0, we use 500 m.u.; and, for a low penalty (Pen), we use a function defining a penalty of $0.250 \%$ per time unit in the initial 8 units of time, $0.429 \%$ per time unit for the subsequent 7 units and a fixed penalty of $5 \%$ if the task takes more than 15 units of time. For the high level $(\mathrm{H})$ 
of these parameters, we use the following values: for a high C2, we use costs of 40 m.u. per unit of time; for a high A2, we use an average advancement rate of 4 work units per unit of time; for a high R0, we use 10000 m.u.; and, for a high penalty (Pen), we use a function defining a penalty of $1.25 \%$ per time unit in the initial 8 units of time, $2.86 \%$ per time unit for the subsequent 7 units and a fixed penalty of $30 \%$ if the task takes more than 15 units of time.

We started by analysing the base scenario, and we initially focused on resource usage as a function of the percentage of work that is completed. The results we obtained, after applying the evaluation procedure and obtaining the best strategy, show that level 2 should be used at the beginning of the task and, while the task is progressing, level 2 is often replaced by level 1 (Fig. 1).

The probability of choosing level 1, when $25 \%, 50 \%, 75 \%$ e $90 \%$ of the work is completed, is $54.57 \%, 58.86 \%, 59.29 \%$ and $59.57 \%$, respectively, when the best strategy is used.

Next we focused on the level of resources that should be being used at each time. We concluded that the average time to finish the task is 10.9 units of time and, under the best strategy, the probability of finishing the task after 5, 10 and 15 units of time is $0.57 \%, 4.43 \%$ and $89.43 \%$, respectively. Figure 2 summarizes the probability of using the different levels of resources as a function of elapsed time.

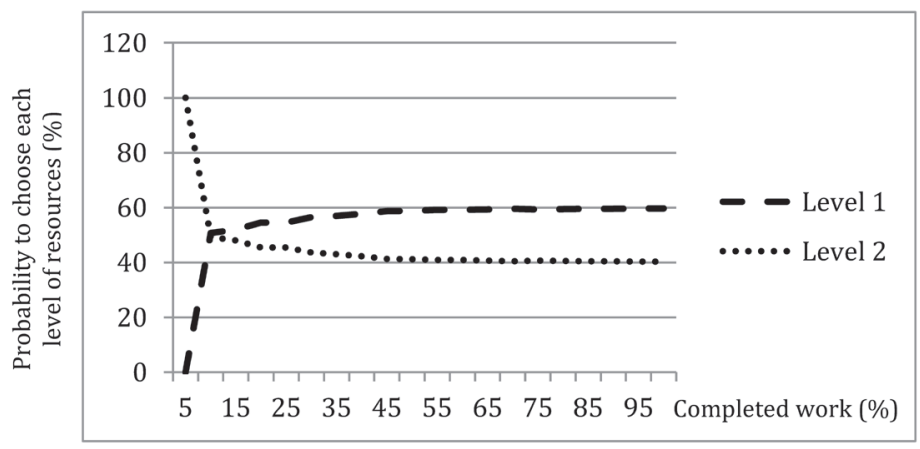

Figure 1: Probability of using each level of resources, for various levels of task completion, in the base scenario. 


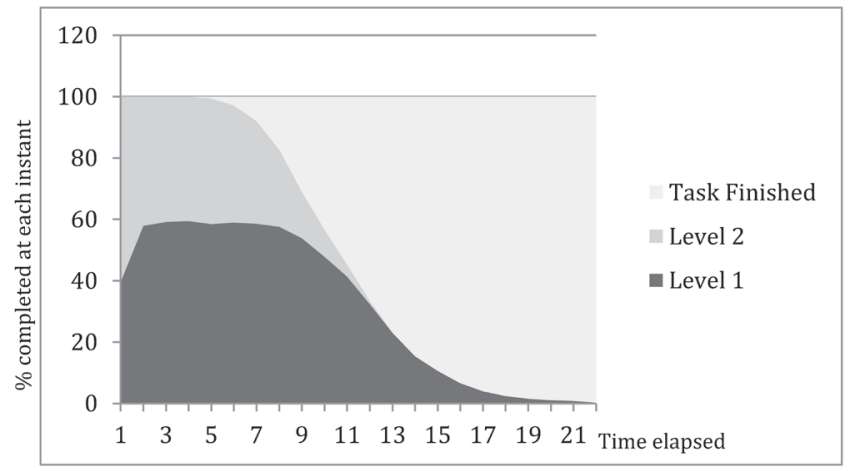

Figure 2: Probabilty of using each level of resources and of finishing the task, as a function of the elapsed time.

We then analysed what would happen in the alternative scenarios defined by considering the alternative parameter values ( $\mathrm{L}$ and $\mathrm{H}$ ), defined before, in order to derive some general rules that may provide managers an idea of what to expect concerning resource usage in the optimal strategy, which maximizes the expected net present value of the task.

At the outset, a larger usage of resource level 2 is expected to lead to a higher probability of completing the task sooner, since level 2 allows a faster average advancement rate of the task. We expect that higher costs of using resource level 2 and lower advancement when using this resource level will lead to a larger utilization of level 1 , since they will make level 1 more attractive when compared to level 2. A lower initial task worth and a lower penalty for late completion are also expected to favour usage of resource level 1 , since they will reduce the the financial benefit of concluding the task earlier.

In order to verify whether our initial expectations would hold, we analysed which level of resources was used in the beginning of the task and the probability of each level of resources being used when different portions of the task were completed. We also analysed what level of resources was being used, or if the task was completed, at different times.

We can point out some scenarios in which level 1 is used exclusively, or almost exclusively. These scenarios are shown in Table 1, in the appendix. Notice that, as expected, the probability of task completion is 
similar in all these scenarios, since the average task advancement with level 1 is not changed among different scenarios, and these scenarios use almost exclusively this level.

There is an interpretation for all the scenarios in Table 1: they correspond to the cases in which the additional benefit of using level 2 does not cover the additional costs. This is usually the case when the costs of level 2 (C2) are high and the average task advancement (A2) is low in this level - level 1 is almost exclusively used in these scenarios, except when both the initial instantaneous task worth (R0) and the penalty (Pen) are high. When C2 is high and A2 is medium, level 1 is almost exclusively used both when R0 is low and when R0 is medium and Pen is not high. When both C2 and A2 are high, level 1 is almost exclusively used only in the case in which both R0 and Pen are low.

When C2 is medium, level 1 is almost exclusively used when: both A2 and $\mathrm{R} 0$ are low; $\mathrm{A} 2$ is low and $\mathrm{R} 0$ is medium; $\mathrm{A} 2$ is medium and $\mathrm{R} 0$ is low; both A2 and Pen are low. Finally, when C2 is low, level 1 is almost exclusively used only if A2 is low and either R0 is low or Pen is low with a medium R0.

Summarizing these results, we can say that a low A2 (a low benefit in the task advancement speed) seems to be the main driver for using level 1 almost exclusively, occurring in 19 out of the 29 scenarios. The following most important factors seems to be low R0, which takes place in 17 scenarios, and high cost C2, which occurs in 15 scenarios. A lower penalty also has some influence in using level 1 almost exclusively, but such influence is smaller, with just 12 scenarios showing it. Notice that these results confirm the prior expectations that low A2, R0 and Pen, and high C2 favour the utilization of resource level 1.

Considering now the scenarios in which level 2 is used almost exclusively, we find 41 such scenarios, which are shown in Table 2 , in the appendix. They correspond to the cases in which there is a large enough benefit of using level 2 to cover the additional costs of using this resource level. 
Making a summarized analysis of the results, high average task advancement in level 2 seems to be the main driver for using level 2 almost exclusively, occurring in 22 out of the 41 scenarios. A low cost in level 2 and a high penalty occur in 20 scenarios, and are the following most important factors. A high initial instantaneous task worth also plays some role in the almost exclusive use of level 2, taking place in 17 scenarios. These results are also in accordance to the initial expectations.

There are 5 scenarios in which level 1 is used at the outset of the task, and level 2 has, subsequently, a significant probability of being selected. These scenarios are shown in Table 3 (in the appendix). In Table 4 (in the appendix) we show the 6 scenarios (including the base scenario) in which level 2 is used at the beginning of the task, and level 1 has, subsequently, a significant probability of being used. All these scenarios correspond to intermediate situations in which there is some balance in the costs and benefits of using level 2 .

The results we obtained confirm the initial expectations, and also show the relative importance of the factors driving the choice of resource levels, and what can be expected in several different situations. In general, the benefit of level 2 in relation to level 1, in terms of advancement speed, seems to be the main driver for the choice of resource level. These results may help managers understanding what they can expect regarding optimal resource utilization, making it easier to formulate expectations concerning future resource availability, without hampering the maximization of the net present value of crucial tasks.

\section{Conclusions and future research}

In this article we consider an approach for defining the best strategy for managing a task, taking into account the maximization of the financial net present value, and apply it to an example of battery development for electric vehicles. This approach assumes that several different processes can be used to develop the task, characterized by different levels of resources, and leading to different average task advancement speed and 
different costs. The approach allows the definition of rules that allow the identification of the best level of resources to be used under each set of circumstances, using a procedure based in LSMC.

The approach is used in several different scenarios, in order to understand the type of management rules that would define the best levels of resources in a battery development project. In particular, we are able to identify several cases in which it seems to be optimal to keep using the same level of resources until the end of the task, and others in which it seems best to adapt the level of resources to the way the task is developing. These rules may help managers forecasting the resources that they will need in the future, without endangering the maximization of the net present value of the most important tasks.

In the future, it would be useful to apply this approach to case study data from a producer of batteries for electric vehicles. This would also allow us to assess the difficulties in calibrating the model and to apply the optimal decisions identified by the model.

It will also be important to incorporate other options that may be relevant for these kinds of tasks, like the abandonment option and the option to delay the beginning of the task. Finally, it is of great relevance to integrate a set of interdependent tasks with this approach, in order to define the best decisions for complete projects, like the project of developing a new electric vehicle.

Acknowledgments: This research was supported by Project EMSURE-Energy and Mobility for Sustainable Regions (CENTRO-07-0224-FEDER-002004)

\section{References}

Cortazar, G., Gravet, M. and Urzua, J. (2008). The valuation of multidimensional American real options using the LSM simulation method. Computers \& Operations Research, pp. 35: 113-129.

Damodaran, A. (2015). Damodaran online - Data: Archives. http://pages.stern.nyu. edu/ adamodar/, accessed February 12th 2015.

Dixit, A. and Pindyck, R. (1993). Investment under uncertainty. New Jersey: Princeton University Press. 
Fialho, J. (2013). Avaliação de Projetos de Investigação e Desenvolvimento na Área das Telecomunicações. Coimbra: Faculdade de Economia da Universidade de Coimbra.

Folta, T. and Miller, K. (2002). Real options in equity partnerships. Strategic Management Journal, 23(1):77-88.

Longstaff, F. and Schwartz, E. (2001). Valuing American Options by Simulation: A Simple Least-Square Approach. The Review of Financial Studies, 14: 1113-1147.

Magalhães, D. (2013). Modelo de Baterias com aplicação em sistemas de gestão de baterias (BMS) de Veículos Eléctrivcos (EVs). Porto: Faculdade de Engenharia da Universidade do Porto.

Santiago, L. P. and Bifano, T. (2005). Management of R\&D projects under uncertainty: a multidimensional approach to managerial flexibility. IEEE Trans. on Eng. Man., 52(2): 269-280.

Su, X. et al. (2014). Silicon-Based Nanomaterials for Lithium-Ion Batteries: A Review. Advanced Energy Materials, 4 (1): 1-23.

Trigeorgis, L. (1993). Real Options and Interactions with Financial Flexibility. Financial Management, 22 (3): 202-224.

Yeo, K. T. and Qiu, F. (2003). The value of management flexibility - a real option approach to investment evaluation. International Journal of Project Management, (21):243-250.

Zeng, X., Li, J. and Singh, N. (2014). Recycling of Spent Lithium-Ion Battery: A Critical Review. Critical Reviews in Environmental Science and Technology, 44(10):1129-1165. 


\section{APPENDIX}

Table 1: Most relevant results concerning the scenarios in which level 1 is used at the beginning of the task, and it is also used exclusively (or almost exclusively) throughout the task.

\begin{tabular}{|c|c|c|c|c|c|c|c|c|c|}
\hline \multirow[b]{2}{*}{$\mathrm{C} 2$} & \multirow[b]{2}{*}{ A2 } & \multirow[b]{2}{*}{ R0 } & \multirow[b]{2}{*}{ Pen } & \multicolumn{3}{|c|}{$\begin{array}{c}\text { Probability of level } 1 \text { being used } \\
\text { when a percentage } x \text { of the task is } \\
\text { completed (in \%) }\end{array}$} & \multicolumn{3}{|c|}{$\begin{array}{c}\text { Probability of the task being } \\
\text { completed for different mo- } \\
\text { ments } T \text { (in \%) }\end{array}$} \\
\hline & & & & $x=25 \%$ & $x=50 \%$ & $x=90 \%$ & $T=5$ & $T=10$ & $T=15$ \\
\hline $\mathrm{L}$ & $\mathrm{L}$ & $\mathrm{L}$ & $\mathrm{L}$ & 100.0 & 100.0 & 100.0 & 0.0 & 12.3 & 74.3 \\
\hline $\mathrm{L}$ & $\mathrm{L}$ & $\mathrm{L}$ & $M$ & 100.0 & 100.0 & 100.0 & 0.0 & 12.1 & 73.6 \\
\hline $\mathrm{L}$ & $\mathrm{L}$ & $\mathrm{L}$ & $\mathrm{H}$ & 100.0 & 100.0 & 100.0 & 0.0 & 14.6 & 73.0 \\
\hline $\mathrm{L}$ & $\mathrm{L}$ & $\mathrm{M}$ & $\mathrm{L}$ & 99.9 & 98.6 & 98.9 & 0.0 & 13.3 & 73.3 \\
\hline$M$ & $\mathrm{~L}$ & $\mathrm{~L}$ & $\mathrm{~L}$ & 100.0 & 100.0 & 100.0 & 0.0 & 11.3 & 73.9 \\
\hline$M$ & $\mathrm{~L}$ & $\mathrm{~L}$ & $M$ & 100.0 & 100.0 & 100.0 & 0.0 & 9.7 & 72.1 \\
\hline$M$ & $\mathrm{~L}$ & $\mathrm{~L}$ & $\mathrm{H}$ & 100.0 & 100.0 & 100.0 & 0.0 & 11.3 & 73.9 \\
\hline $\mathrm{M}$ & $\mathrm{L}$ & $\mathrm{M}$ & $\mathrm{L}$ & 100.0 & 100.0 & 100.0 & 0.0 & 11.3 & 73.9 \\
\hline$M$ & $\mathrm{~L}$ & $\mathrm{M}$ & $M$ & 100.0 & 100.0 & 99.7 & 0.1 & 14.0 & 71.9 \\
\hline $\mathrm{M}$ & $\mathrm{L}$ & $\mathrm{M}$ & $\mathrm{H}$ & 100.0 & 99.6 & 99.4 & 0.0 & 13.1 & 70.4 \\
\hline $\mathrm{M}$ & $\mathrm{L}$ & $\mathrm{H}$ & $\mathrm{L}$ & 98.6 & 96.3 & 99.4 & 0.0 & $\begin{array}{l}12.7 \\
\end{array}$ & 73.2 \\
\hline$M$ & $M$ & $\mathrm{~L}$ & $\mathrm{~L}$ & 100.0 & 100.0 & 100.0 & 0.0 & 13.7 & 72.9 \\
\hline $\mathrm{M}$ & $M$ & $\mathrm{~L}$ & $M$ & 100.0 & 100.0 & 100.0 & 0.0 & 13.7 & 72.9 \\
\hline $\mathrm{M}$ & $M$ & $\mathrm{~L}$ & $\mathrm{H}$ & 98.9 & 98.6 & 98.4 & 0.0 & 13.0 & 70.1 \\
\hline $\mathrm{H}$ & $\mathrm{L}$ & $\mathrm{L}$ & $\mathrm{L}$ & 100.0 & 100.0 & 100.0 & 0.0 & 14.1 & 75.0 \\
\hline $\mathrm{H}$ & $\mathrm{L}$ & $\mathrm{L}$ & $M$ & 100.0 & 100.0 & 100.0 & 0.0 & 9.7 & 72.1 \\
\hline $\mathrm{H}$ & $\mathrm{L}$ & $\mathrm{L}$ & $\mathrm{H}$ & 100.0 & 100.0 & 100.0 & 0.0 & 13.9 & 71.7 \\
\hline $\mathrm{H}$ & $\mathrm{L}$ & $\mathrm{M}$ & $\mathrm{L}$ & 100.0 & 100.0 & 100.0 & 0.0 & $\begin{array}{l}11.7 \\
\end{array}$ & 72.0 \\
\hline $\mathrm{H}$ & $\mathrm{L}$ & $M$ & $M$ & 100.0 & 100.0 & 100.0 & 0.0 & 13.7 & 72.4 \\
\hline $\mathrm{H}$ & $\mathrm{L}$ & $\mathrm{M}$ & $\mathrm{H}$ & 100.0 & 100.0 & 100.0 & 0.0 & 14.3 & 76.0 \\
\hline $\mathrm{H}$ & $\mathrm{L}$ & $\mathrm{H}$ & $\mathrm{L}$ & 100.0 & 99.6 & 99.9 & 0.0 & 11.7 & 72.0 \\
\hline $\mathrm{H}$ & $\mathrm{L}$ & $\mathrm{H}$ & $M$ & 97.3 & 100.0 & 99.7 & 0.1 & 11.9 & 72.0 \\
\hline $\mathrm{H}$ & M & $\mathrm{L}$ & $\mathrm{L}$ & 100.0 & 100.0 & 100.0 & 0.0 & 12.6 & 75.1 \\
\hline $\mathrm{H}$ & $M$ & $\mathrm{~L}$ & $M$ & 100.0 & 100.0 & 100.0 & 0.0 & 13.4 & 74.9 \\
\hline $\mathrm{H}$ & $M$ & $\mathrm{~L}$ & $\mathrm{H}$ & 100.0 & 100.0 & 100.0 & 0.0 & 12.7 & 73.9 \\
\hline $\mathrm{H}$ & $M$ & $\mathrm{M}$ & $\mathrm{L}$ & 100.0 & 99.7 & 100.0 & 0.0 & 13.4 & 70.4 \\
\hline $\mathrm{H}$ & $M$ & $M$ & $M$ & 99.7 & 100.0 & 99.6 & 0.0 & 13.4 & 73.9 \\
\hline $\mathrm{H}$ & $\mathrm{H}$ & $\mathrm{L}$ & $\mathrm{L}$ & 100.0 & 100.0 & 100.0 & 0.0 & 13.9 & 73.0 \\
\hline $\mathrm{H}$ & $\mathrm{H}$ & $\mathrm{L}$ & $M$ & 100.0 & 99.7 & 99.7 & 0.0 & 11.00 & 73.3 \\
\hline
\end{tabular}


Table 2: Most relevant results concerning the scenarios in which level 2 is used at the beginning of the task, and it is also used exclusively (or almost exclusively) throughout the task.

\begin{tabular}{|c|c|c|c|c|c|c|c|c|c|}
\hline \multirow[b]{2}{*}{$\mathrm{C} 2$} & \multirow[b]{2}{*}{ A2 } & \multirow[b]{2}{*}{ R0 } & \multirow[b]{2}{*}{ Pen } & \multicolumn{3}{|c|}{$\begin{array}{l}\text { Probability of level } 2 \text { being used } \\
\text { when a percentage } x \text { of the task is } \\
\text { completed (in \%) }\end{array}$} & \multicolumn{3}{|c|}{$\begin{array}{c}\text { Probability of the task being } \\
\text { completed for different mo- } \\
\text { ments } T \text { (in \%) }\end{array}$} \\
\hline & & & & $x=25 \%$ & $x=50 \%$ & $x=90 \%$ & $T=5$ & $T=10$ & $T=15$ \\
\hline $\mathrm{H}$ & $\mathrm{H}$ & $\mathrm{H}$ & $\mathrm{H}$ & 99.4 & 95.3 & 99.7 & 49.2 & 99.9 & 100.0 \\
\hline $\mathrm{H}$ & $\mathrm{H}$ & $\mathrm{H}$ & M & 96.7 & 98.9 & 98.0 & 47.6 & 99.6 & 99.9 \\
\hline $\mathrm{H}$ & $\mathrm{H}$ & M & $\mathrm{H}$ & 99.7 & 100.0 & 98.6 & 53.1 & 100.0 & 100.0 \\
\hline $\mathrm{H}$ & $\mathrm{H}$ & M & M & 99.0 & 99.1 & 94.0 & 51.2 & 99.0 & 99.9 \\
\hline $\mathrm{H}$ & $\mathrm{H}$ & $\mathrm{L}$ & $\mathrm{H}$ & 100.0 & 97.4 & 93.7 & 47.2 & 98.6 & 100.0 \\
\hline $\mathrm{H}$ & $\mathrm{M}$ & $\mathrm{H}$ & $\mathrm{H}$ & 99.7 & 99.7 & 99.4 & 2.4 & 86.7 & 99.9 \\
\hline $\mathrm{H}$ & $\mathrm{M}$ & $\mathrm{M}$ & $\mathrm{H}$ & 99.6 & 97.9 & 92.6 & 1.4 & 84.7 & 99.6 \\
\hline $\mathrm{H}$ & $\mathrm{L}$ & $\mathrm{H}$ & $\mathrm{H}$ & 98.1 & 94.9 & 94.0 & 0.0 & 35.4 & 93.0 \\
\hline M & $\mathrm{H}$ & $\mathrm{H}$ & $\mathrm{H}$ & 100.0 & 100.0 & 99.7 & 53.4 & 100.0 & 100.0 \\
\hline $\mathrm{M}$ & $\mathrm{H}$ & $\mathrm{H}$ & $\mathrm{M}$ & 100.0 & 100.0 & 100.0 & 52.3 & 100.0 & 100.0 \\
\hline $\mathrm{M}$ & $\mathrm{H}$ & $M$ & $\mathrm{H}$ & 100.0 & 100.0 & 100.0 & 52.1 & 100.0 & 100.0 \\
\hline $\mathrm{M}$ & $\mathrm{H}$ & $\mathrm{M}$ & $\mathrm{M}$ & 99.7 & 100.0 & 99.4 & 49.4 & 99.9 & 100.0 \\
\hline M & $\mathrm{H}$ & M & $\mathrm{L}$ & 99.4 & 99.4 & 96.0 & 52.9 & 99.3 & 99.7 \\
\hline M & $\mathrm{H}$ & $\mathrm{L}$ & $\mathrm{H}$ & 100.0 & 100.0 & 100.0 & 56.0 & 100.0 & 100.0 \\
\hline $\mathrm{M}$ & $\mathrm{H}$ & $\mathrm{L}$ & $\mathrm{M}$ & 100.0 & 100.0 & 100.0 & 55.6 & 99.0 & 100.0 \\
\hline $\mathrm{M}$ & $\mathrm{H}$ & $\mathrm{L}$ & $\mathrm{L}$ & 100.0 & 100.0 & 100.0 & 56.6 & 100.0 & 100.0 \\
\hline $\mathrm{M}$ & $\mathrm{M}$ & $\mathrm{H}$ & $\mathrm{H}$ & 100.0 & 100.0 & 100.0 & 1.6 & 85.4 & 100.0 \\
\hline M & M & $\mathrm{H}$ & M & 94.6 & 100.0 & 98.6 & 2.3 & 88.1 & 99.9 \\
\hline M & M & $\mathrm{H}$ & $\mathrm{L}$ & 97.0 & 98.1 & 95.4 & 1.6 & 85.0 & 99.6 \\
\hline $\mathrm{M}$ & $\mathrm{M}$ & $\mathrm{M}$ & $\mathrm{H}$ & 100.0 & 100.0 & 100.0 & 2.4 & 88.4 & 99.9 \\
\hline $\mathrm{M}$ & $\mathrm{L}$ & $\mathrm{H}$ & $\mathrm{H}$ & 99.9 & 97.7 & 96.6 & 0.1 & 33.9 & 93.4 \\
\hline $\mathrm{L}$ & $\mathrm{H}$ & $\mathrm{H}$ & $\mathrm{H}$ & 100.0 & 100.0 & 97.7 & 50.0 & 100.0 & 100.0 \\
\hline $\mathrm{L}$ & $\mathrm{H}$ & $\mathrm{H}$ & $\mathrm{M}$ & 99.9 & 100.0 & 100.0 & 49.9 & 100.0 & 100.0 \\
\hline $\mathrm{L}$ & $\mathrm{H}$ & $\mathrm{H}$ & $\mathrm{L}$ & 97.0 & 98.9 & 100.0 & 48.4 & 99.0 & 100.0 \\
\hline $\mathrm{L}$ & $\mathrm{H}$ & $\mathrm{M}$ & $\mathrm{H}$ & 99.9 & 100.0 & 100.0 & 53.3 & 100.0 & 100.0 \\
\hline $\mathrm{L}$ & $\mathrm{H}$ & $M$ & $\mathrm{M}$ & 100.0 & 100.0 & 100.0 & 50.9 & 100.0 & 100.0 \\
\hline $\mathrm{L}$ & $\mathrm{H}$ & M & $\mathrm{L}$ & 99.9 & 99.9 & 99.6 & 54.4 & 100.0 & 100.0 \\
\hline $\mathrm{L}$ & $\mathrm{H}$ & $\mathrm{L}$ & $\mathrm{H}$ & 100.0 & 100.0 & 100.0 & 53.0 & 100.0 & 100.0 \\
\hline $\mathrm{L}$ & $\mathrm{H}$ & $\mathrm{L}$ & M & 100.0 & 100.0 & 100.0 & 54.3 & 99.9 & 100.0 \\
\hline $\mathrm{L}$ & $\mathrm{H}$ & $\mathrm{L}$ & $\mathrm{L}$ & 100.0 & 100.0 & 100.0 & 53.0 & 100.0 & 100.0 \\
\hline $\mathrm{L}$ & $\mathrm{M}$ & $\mathrm{H}$ & $\mathrm{H}$ & 100.0 & 99.9 & 99.9 & 2.3 & 88.0 & 100.0 \\
\hline $\mathrm{L}$ & $\mathrm{M}$ & $\mathrm{H}$ & $\mathrm{M}$ & 91.1 & 96.6 & 97.1 & 2.8 & 86.0 & 98.9 \\
\hline $\mathrm{L}$ & M & $\mathrm{H}$ & $\mathrm{L}$ & 82.7 & 96.9 & 100.0 & 2.0 & 79.7 & 99.4 \\
\hline $\mathrm{L}$ & M & M & $\mathrm{H}$ & 100.0 & 100.0 & 100.0 & 3.9 & 88.0 & 100.0 \\
\hline $\mathrm{L}$ & $\mathrm{M}$ & $\mathrm{M}$ & $\mathrm{M}$ & 100.0 & 100.0 & 100.0 & 3.4 & 86.6 & 99.9 \\
\hline $\mathrm{L}$ & $M$ & $M$ & $\mathrm{~L}$ & 97.0 & 99.0 & 97.1 & 3.1 & 86.4 & 99.3 \\
\hline $\mathrm{L}$ & $\mathrm{M}$ & $\mathrm{L}$ & $\mathrm{H}$ & 100.0 & 100.0 & 100.0 & 4.1 & 87.3 & 99.7 \\
\hline $\mathrm{L}$ & M & $\mathrm{L}$ & M & 100.0 & 99.7 & 99.7 & 4.2 & 87.3 & 99.6 \\
\hline $\mathrm{L}$ & M & $\mathrm{L}$ & $\mathrm{L}$ & 100.0 & 100.0 & 99.9 & 2.7 & 87.1 & 99.9 \\
\hline $\mathrm{L}$ & $\mathrm{L}$ & $\mathrm{M}$ & $\mathrm{H}$ & 98.4 & 99.1 & 98.7 & 0.3 & 51.2 & 94.3 \\
\hline $\mathrm{L}$ & $\mathrm{L}$ & $\mathrm{H}$ & $\mathrm{H}$ & 100.0 & 100.0 & 99.7 & 0 & 20.6 & 92.6 \\
\hline
\end{tabular}


Table 3: Most relevant results concerning the scenarios in which level 1 is used at the beginning of the task, and there is a significant probability of level 2 being used throughout the task.

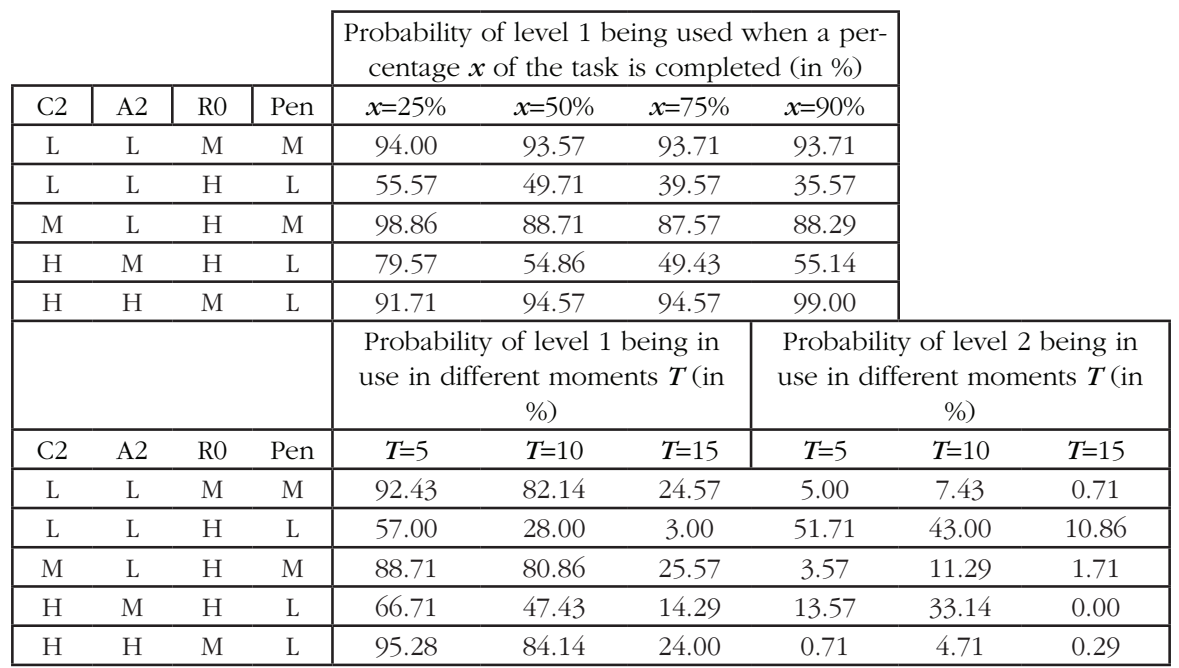

Table 4: Most relevant results concerning the scenarios in which level 2 is used at the beginning of the task, and there is a significant probability of level 1 being used throughout the task.

\begin{tabular}{|c|c|c|c|c|c|c|c|c|c|}
\hline \multirow[b]{2}{*}{$\mathrm{C} 2$} & \multirow[b]{2}{*}{ A2 } & \multirow[b]{2}{*}{ R0 } & \multirow[b]{2}{*}{ Pen } & \multicolumn{4}{|c|}{$\begin{array}{l}\text { Probability of level } 1 \text { being used when a per- } \\
\text { centage } x \text { of the task is completed (in \%) }\end{array}$} & & \\
\hline & & & & $x=25 \%$ & $x=50 \%$ & $x=75 \%$ & $x=90 \%$ & & \\
\hline $\mathrm{L}$ & $\mathrm{L}$ & $\mathrm{H}$ & M & 12.29 & 23.43 & 22.29 & 16.43 & & \\
\hline $\mathrm{M}$ & M & $\mathrm{M}$ & $\mathrm{L}$ & 2.14 & 29.86 & 46.14 & 44.14 & & \\
\hline $\mathrm{M}$ & $\mathrm{M}$ & $\mathrm{M}$ & $\mathrm{M}$ & 54.57 & 58.86 & 59.29 & 59.57 & & \\
\hline $\mathrm{M}$ & $\mathrm{H}$ & $\mathrm{H}$ & $\mathrm{L}$ & 23.29 & 8.29 & 15.43 & 9.43 & & \\
\hline $\mathrm{H}$ & M & $\mathrm{H}$ & $\mathrm{M}$ & 20.43 & 12.86 & 13.00 & 16.43 & & \\
\hline \multirow[t]{2}{*}{$\mathrm{H}$} & $\mathrm{H}$ & $\mathrm{H}$ & $\mathrm{L}$ & 32.71 & 32.71 & 2.29 & 3.14 & & \\
\hline & & & & \multicolumn{3}{|c|}{$\begin{array}{l}\text { Probability of level } 1 \text { being in } \\
\text { use in different moments } T \text { (in } \\
\% \text { ) }\end{array}$} & \multicolumn{3}{|c|}{$\begin{array}{c}\text { Probability of level } 2 \text { being in } \\
\text { use in different moments } T \text { (in } \\
\% \text { ) }\end{array}$} \\
\hline $\mathrm{C} 2$ & $\mathrm{~A} 2$ & R0 & Pen & $T=5$ & $T=10$ & $T=15$ & $T=5$ & $T=10$ & $T=15$ \\
\hline $\mathrm{L}$ & $\mathrm{L}$ & $\mathrm{H}$ & $\mathrm{M}$ & 20.29 & 20.71 & 8.00 & 79.71 & 46.29 & 3.00 \\
\hline $\mathrm{M}$ & $\mathrm{M}$ & $\mathrm{M}$ & $\mathrm{L}$ & 46.43 & 13.86 & 0.00 & 53.57 & 22.29 & 0.43 \\
\hline $\mathrm{M}$ & $\mathrm{M}$ & $\mathrm{M}$ & $\mathrm{M}$ & 58.43 & 47.86 & 10.57 & 41.00 & 8.71 & 0.00 \\
\hline$M$ & $\mathrm{H}$ & $\mathrm{H}$ & $\mathrm{L}$ & 16.00 & 0.71 & 0.14 & 53.00 & 1.29 & 0.83 \\
\hline $\mathrm{H}$ & M & $\mathrm{H}$ & $\mathrm{M}$ & 19.14 & 13.29 & 4.00 & 79.14 & 10.71 & 0.14 \\
\hline $\mathrm{H}$ & $\mathrm{H}$ & $\mathrm{H}$ & $\mathrm{L}$ & 30.29 & 3.14 & 2.28 & 36.71 & 5.29 & 0.00 \\
\hline
\end{tabular}


Série Investigação

Imprensa da Universidade de Coimbra

Coimbra University Press

2015

mais

Programa Operacional Regional do Centro

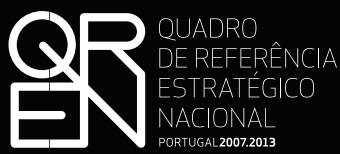

PORTUGAL 2007.2013

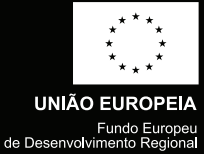

- $\mathbf{U}$

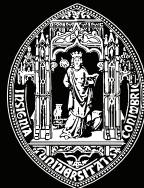

C •

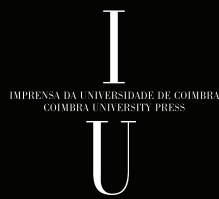

